\title{
Ceramides: Shared Lipid Biomarkers of Cardiovascular Disease and Schizophrenia
}

\author{
Церамиды: общие липидные биомаркеры сердечно-сосудистых \\ заболеваний и шизофрении \\ DOI:10.17816/CP101
}

Original article

Anna I. Tkachev, ${ }^{1}$ Elena A. Stekolshchikova, ${ }^{1}$ Anna Yu. Morozova, ${ }^{2,3}$ Nikolay A. Anikanov, ${ }^{1}$ Yana A. Zorkina, ${ }^{2,3}$ Polina N. Alekseyeva, ${ }^{3}$ Elena B. Khobta, ${ }^{3}$ Denis S. Andreyuk, ${ }^{3}$ Svetlana A. Zozulya, ${ }^{4}$ Alexandra N. Barkhatova, ${ }^{4}$ Tatiana P. Klyushnik, ${ }^{4}$ Alexander M. Reznik, ${ }^{3,5}$ Georgiy P. Kostyuk, ${ }^{3}$ Philipp E. Khaitovich ${ }^{1}$

${ }^{1}$ V. Zelman Center for Neurobiology and Brain Restoration, Skolkovo Institute of Science and Technology, Moscow, Russia; ${ }^{2}$ Department of Basic and Applied Neurobiology, V. Serbsky Federal Medical Research Centre of Psychiatry and Narcology, Moscow, Russia;

${ }^{3}$ Mental-health Clinic No. 1 named after N.A. Alexeev of Moscow Healthcare Department, Moscow, Russia;

${ }^{4}$ Mental Health Research Center of Russian Academy of Medical Sciences, Moscow, Russia;

${ }^{5}$ Moscow State University of Food Production, Moscow, Russia

The article can be used under the CC BY-NC-ND 4.0 license (c) Authors, 2021

\begin{abstract}
Анна И. Ткачев, ${ }^{1}$ Елена А. Стекольщикова, ${ }^{1}$ Анна Ю. Морозова,, ${ }^{2,3}$ Николай А. Аниканов, ${ }^{1}$ Яна А. Зоркина, ${ }^{2,3}$ Полина Н. Алексеева, ${ }^{3}$ Елена Б. Хобта, ${ }^{3}$ Денис С. Андреюк, ${ }^{3}$ Светлана А. Зозуля, ${ }^{4}$ Александра Н. Бархатова, ${ }^{4}$ Татьяна П. Клюшник, ${ }^{4}$ Александр М. Резник, ${ }^{3,5}$ Георгий П. Костюк, ${ }^{3}$ Филипп Е. Хаитович ${ }^{1}$

${ }^{1}$ Сколковский институт науки и технологий, чентр нейробиологии и нейрореабилитации, Москва, Россия; ${ }^{2}$ ФГБУ «Национальный медицинский исследовательский центр психиатрии и наркологии имени В.П. Сербского» Министерства здравоохранения Российской Федерации, Москва, Россия;

${ }^{3}$ ГБУЗ «Психиатрическая клиническая больница № 1 им. Н.А. Алексеева Департамента здравоохранения города Москвы', Москва, Россия;

4 ФГБНУ «Научный чентр психического здоровья», Москва, Россия;

${ }^{5}$ ФГБОУ ВО «Московский государственный университет пишевых производств», Москва, Россия
\end{abstract}

Лицензия CC BY-NC-ND 4.0 ( Коллектив авторов, 2021

\section{ABSTRACT}

INTRODUCTION: Schizophrenia, although a debilitating mental illness, greatly affects individuals' physical health as well. One of the leading somatic comorbidities associated with schizophrenia is cardiovascular disease, which has been estimated to be one of the leading causes of excess mortality in patients diagnosed with schizophrenia. Although the shared susceptibility to schizophrenia and cardiovascular disease is well established, the mechanisms linking these two disorders are not well understood. Genetic studies have hinted toward shared lipid metabolism abnormalities co-occurring in the two disorders, while lipid compounds have emerged as prognostic markers for cardiovascular disease. In particular, three ceramide species in the blood plasma, Cer(d18:1/16:0), Cer(d18:1/18:0), and $\operatorname{Cer}(\mathrm{d} 18: 1 / 24: 1)$, have been robustly linked to the latter disorder.

AlM: We aimed to assess the differences in abundances of $\operatorname{Cer}(\mathrm{d} 18: 1 / 16: 0), \operatorname{Cer}(\mathrm{d} 18: 1 / 18: 0)$, and $\operatorname{Cer}(\mathrm{d} 18: 1 / 24: 1)$ in the blood plasma of schizophrenia patients compared to healthy controls. 
METHODS: We measured the abundances of Cer(d18:1/16:0), Cer(d18:1/18:0), and $\operatorname{Cer}(\mathrm{d} 18: 1 / 24: 1)$ in a cohort of 82 patients with schizophrenia and 138 controls without a psychiatric diagnosis and validated the results using an independent cohort of 26 patients with schizophrenia, 55 control individuals, and 19 patients experiencing a first psychotic episode.

RESULTS: We found significant alterations for all three ceramide species Cer(d18:1/16:0), Cer(d18:1/18:0), and Cer(d18:1/24:1) and a particularly strong difference in concentrations between psychiatric patients and controls for the ceramide species Cer(d18:1/18:0).

CONCLUSIONS: The alteration of $\operatorname{Cer}(\mathrm{d} 18: 1 / 16: 0), \operatorname{Cer}(\mathrm{d} 18: 1 / 18: 0)$, and $\operatorname{Cer}(\mathrm{d} 18: 1 / 24: 1)$ levels in the blood plasma might be a manifestation of metabolic abnormalities common to both schizophrenia and cardiovascular disease.

\section{АННОТАЦИЯ}

АКТУАЛЬНОсть: Шизофрения является не только психическим заболеванием, но и влияет на физическое здоровье людей. Одними из основных сопутствующих соматических заболеваний, связанных с шизофренией, являются сердечно-сосудистые заболевания, считающиеся одной из основных причин повышенной смертности у пациентов с диагнозом шизофрения. Хотя общая предрасположенность к шизофрении и сердечнососудистым заболеваниям хорошо известна, механизмы, связывающие эти два расстройства, недостаточно изучены. Генетические исследования указали на общие аномалии липидного обмена, сопутствующие этим двум расстройствам, в то время как липидные соединения были идентифицированы как прогностические маркеры сердечно-сосудистых заболеваний. В частности, три представителя церамидов, определенной группы липидов, в плазме крови, Cer (d18: 1/16: 0), Cer (d18: 1/18: 0) и Cer (d18: 1/24: 1), были ассоциированы с риском сердечно-сосудистых заболеваний.

ЦЕЛИ: Мы оценивали различия в содержании Cer (d18: 1/16: 0), Cer (d18: 1/18: 0) и Cer (d18: 1/24: 1) в плазме крови больных шизофренией по сравнению с контрольной группой.

МАТЕРИАЛ И МЕТОДЫ: МЫ Измерили содержание Cer (d18: 1/16: 0), Cer (d18: 1/18: 0) и Cer (d18: 1/24: 1) в когорте из 82 пациентов с шизофренией и 138 человек из контрольной группы без психиатрического диагноза и, далее, подтвердили результаты анализа в слепом исследовании независимой когорты из 26 пациентов с шизофренией, 55 человек из контрольной группы и 19 пациентов, перенесших первый психотический эпизод.

РЕзУльтАТЫ: Мы обнаружили значительные изменения для всех трех видов церамидов Cer (d18: 1/16: 0), Cer (d18: 1/18: 0) и Cer (d18: 1/24: 1). Среди этих соединений Cer (d18: 1/18: 0) показал наиболее сильные наибольшую разницу между пациентами и контрольной группой.

выводы: Изменение уровней Cer (d18: 1/16: 0), Cer (d18: 1/18: 0) и Cer (d18: 1/24: 1) в плазме крови может быть проявлением метаболических аномалий, общих для как шизофрении, так и сердечно-сосудистых заболеваний.

Keywords: ceramide; schizophrenia; cardiovascular disease; lipid; blood plasma

Ключевые слова: церамиды; шизофрения; сердечно-сосудистые заболевания; липиды; плазма крови

\section{INTRODUCTION}

Schizophrenia (SCZ) is a debilitating mental illness affecting the individual's thinking, perception, emotional response, as well as daily functioning, in general. Individuals diagnosed with schizophrenia are also at increased risk of somatic comorbidities, such as cardiovascular disease (CVD), type 2 diabetes, and obesity. ${ }^{1,2}$ It has been estimated that patients with schizophrenia show a two-fold increase in mortality compared to the general population. ${ }^{3}$ Most of this excess 
mortality can be attributed to physical illnesses, with CVD being one of the leading causes of death. ${ }^{3-5}$

Understanding the mechanisms of CVD development in individuals with schizophrenia is of extreme importance for the management and treatment of the disorder. While lifestyle and antipsychotic medication can affect the risk of CVD, ${ }^{5}$ there seems to be an intrinsic and complex relationship between this physical disorder and schizophrenia. Genetic pleiotropy has been reported for schizophrenia and cardiometabolic abnormalities, ${ }^{6-10}$ implying shared genetic risk factors for CVD and SCZ. Stratification by genetic susceptibility to cardiometabolic abnormalities has also been proposed to separate SCZ patients into subgroups with differing metabolic profiles. ${ }^{11}$ At the same time, even though genetic studies show hints of a shared susceptibility towards both SCZ and CVD, the mechanisms linking these two disorders are difficult to untangle from genetic information alone. In this respect, quantifying metabolic profiles of compounds associated with CVD in individuals diagnosed with SCZ can deepen the understanding of this connection by identifying the abnormalities common to the two disorders. Lipids, in particular, have been shown to undergo substantial alterations in schizophrenia. ${ }^{12}$ Further, genetic variants exhibiting pleiotropic effects in SCZ and CVD are particularly enriched in genes involved in lipid metabolism. ${ }^{9,10}$

While classical lipid measurements, such as low-density lipoproteins (LDL), high-density lipoproteins (HDL), and total triglycerides, are well known to be associated with both $\mathrm{CVD}^{13}$ and $\mathrm{SCZ}_{1}{ }^{14-16}$ advances in lipidomics have provided the opportunity to expand the scope of metabolic profiling and deepen our understanding of lipid alterations in disease. Ceramides, a class of lipids that consist of a sphingosine backbone connected by an amide bond to a fatty acid (FA) chain of varying length have been shown to predict cardiovascular events more effectively than classical lipid measurements. ${ }^{17}$ In particular, three lipid species, Cer(d18:1/16:0), $\operatorname{Cer}(\mathrm{d} 18: 1 / 18: 0)$, and $\operatorname{Cer}(\mathrm{d} 18: 1 / 24: 1)$, have been proposed as promising biomarkers of CVD. ${ }^{18}$ To assess whether disruption in the metabolism of these ceramides is also characteristic of patients with SCZ, we investigated the levels of these three lipids in 82 patients diagnosed with SCZ in comparison to 138 control (CTL) individuals without a psychiatric diagnosis. We further validated the results on an independent dataset of $26 \mathrm{SCZ}$ patients, and
55 CTL patients, as well as 19 patients exhibiting a first episode of psychosis (FEP).

\section{METHODS}

Main sample cohort

Subjects included in this cohort were inpatients recruited from the Mental Health Research Centre, Moscow. The cohort included adult (18 or more years of age) participants with a diagnosis of SCZ ( $n=82$; age 31.2 \pm 8.4 ; $23 \%$ female). SCZ status was determined based on the International Classification of Disease (ICD-10). The exclusion criteria were being less than 18 years old, severe somatic and neurological illness, recent surgery, pregnancy, history of substance and alcohol abuse, acute heart failure, severe chronic heart failure, and a diagnosis of CVD. Sample collection was performed at the Neuroimmunology Laboratory of the Mental Health Research Centre, Moscow. The control group ( $n=138$; age $29.5 \pm 8.3 ; 22 \%$ female) consisted of healthy volunteers from the Mental Health Research Centre who were showing no signs of psychiatric disorders and met the same exclusion criteria at above (less than 18 years of age, family history of any psychiatric disorder, severe somatic and neurological illness, recent surgery, pregnancy, substance and alcohol abuse acute heart failure, severe chronic heart failure, a diagnosis of CVD). Patients and healthy participants were evaluated by board-certified psychiatrists from the same centre, whilst somatic condition was assessed by internists of the respective specialties. The study was approved by the local ethics committee of the Mental Health Research Centre (Protocol No. 281; 05/05/2016). Informed consent was obtained from all participants. The entire study was conducted in line with the World Medical Association Declaration of Helsinki formulating ethical principles for medical research involving human subjects.

\section{Validation sample cohort}

Participants included in the validation cohort were inpatients diagnosed with a first episode of psychosis (FEP, $n=19$, age $27 \pm 7,53 \%$ female) and schizophrenia (SCZ, $n=26$, age $35 \pm 12,58 \%$ female), as recruited at Mental Health Clinic No. 1, named after N.A. Alexeev.

Exclusion criteria for patients were being less than 18 years of age, having a serious medical or surgical illness, any previous episodes of psychosis due to substance abuse, acute heart failure, severe chronic heart failure, 
and psychotic symptomatology within a clearly diagnosed affective or borderline personality disorder. For healthy controls, the exclusion criteria were being less than 18 years of age, having a current or previous psychiatric disorder, a family history of any psychiatric disorder, head trauma, neurological illness, serious medical or surgical illness, or a history of substance abuse. SCZ status was determined based on the International Classification of Disease (ICD-10). Patients were evaluated using a structured interview for the Positive and Negative Syndrome Scale (PANSS), including the PANSS positive, PANSS negative, and PANSS general psychopathology subscales. The average total PANSS was determined to be $98 \pm 24$ for women and $91 \pm 22$ for men. The Russian version of PANSS, with acceptable validity and reliability, was used to evaluate the severity of the symptoms of psychosis in the schizophrenia patients in this study. ${ }^{19}$

The control group (CTL, $n=55$; age $32 \pm 8,35 \%$ female) consisted of healthy volunteers who had no apparent signs of any psychiatric disorders and met the same exclusion criteria (aged less than 18 years old, family history of any psychiatric disorder, severe somatic and neurological illness, recent surgery, pregnancy, history of substance and/or alcohol abuse, acute heart failure, severe chronic heart failure).

CTL and SZ had no addictions including $<80 \mathrm{mg}$ of ethanol equivalent per week and $<10$ cigarettes per day. Informed consent was obtained from all participants. The protocol for this study was approved by the Interdisciplinary Ethics Committee, Moscow (Protocol No.1, 22/07/2017).

\section{Lipid measurements}

Plasma was obtained from peripheral venous blood in the morning from individuals that had undergone an overnight fast. Plasma samples were collected in $4 \mathrm{ml}$ Vacutainer tubes containing the chelating agent ethylenediaminetetraacetic acid (EDTA) (BD Vacutainer, Franklin Lakes, NJ, US). Tubes were centrifuged at $4^{\circ} \mathrm{C}$ at $1100 \mathrm{~g}$ for $15 \mathrm{~min}$. The supernatant was stored immediately in $500 \mu \mathrm{l}$ aliquots at $-80^{\circ} \mathrm{C}$. We collected the blood plasma samples from the main cohort comprising 82 SCZ and 138 CTL individuals (SCZ: age $31 \pm 8,23 \%$ female; CTL: age $30 \pm 8,22 \%$ female). We further collected a validation cohort including samples from 26 SCZ, 19 FEP, and 55 CTL individuals (SCZ: age $35 \pm 12,58 \%$ female; FEP: age $27 \pm 7,53 \%$ female; CTL: age $32 \pm 8,35 \%$ female). Studies on the validation of the data obtained were conducted using the blind method, i.e., during the measurement of the lipid profile, the experimenter did not know which sample (patients or controls) he/she was measuring. We randomized the plasma samples with respect to the diagnosis and extracted lipids from them following the same standardized extraction procedure. We then measured lipid abundances using liquid chromatography coupled with mass spectrometry (LC-MS) in negative ionization mode for the main dataset and validation dataset in two distinct experimental runs. Sample processing, LC-MS measurements, and data preprocessing were performed as described elsewhere. ${ }^{48}$ We determined the molecular ions corresponding to $\operatorname{Cer}(\mathrm{d} 18: 1 / 16: 0)$, Cer(d18:1/18:0), and Cer(d18:1/24:1) based on their initial molecular ion masses, chromatography retention time, and their fragmentation profiles (LC-MS²) by the presence of characteristic sphingoid base fragments.

To simplify the normalization of lipid abundances between the main and validation datasets, 20 demographically representative reference samples from the main dataset were remeasured together with the validation dataset. The mean abundances of these samples in the validation and main datasets were used to normalize the abundances in the validation dataset: for each lipid, the differences between these means were subtracted from the abundances of each sample in the validation dataset to produce normalized abundances.

\section{Statistical analysis}

Statistical tests were performed on the base-two log transformed abundances to ensure normal distribution. The Welch t-test of unequal variance was used to assess statistical differences. However, bar plots were visualized on the original scale.

Analysis, including statistical analysis, performance calculation for naïve classifiers, and logistic regression, was performed using the publicly available python libraries "scipy" and "sklearn". The prediction models were trained using the main dataset, and tested on both the main and validation datasets.

\section{RESULTS}

The statistical analyses of the lipids extracted from main cohort SCZ and CTL samples demonstrated that all three

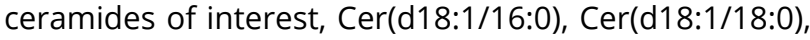




\begin{tabular}{|c|c|c|c|c|}
\hline & Ceramide spices & Cer(d18:1/16:0) & Cer(d18:1/18:0) & Cer(d18:1/24:1) \\
\hline \multirow{3}{*}{ p-values } & SCZ vs CTL, main & $<0,001$ & $<0,001$ & $<0,001$ \\
\hline & SCZ vs CTL, validation & 0,44 & 0,001 & 0,16 \\
\hline & FEP vs CTL, validation & 0,012 & $<0,001$ & 0,02 \\
\hline \multirow{3}{*}{ Fold-changes } & SCZ vs CTL, main & 1,17 & 1,63 & 1,21 \\
\hline & SCZ vs CTL, validation & 1,08 & 1,76 & 1,08 \\
\hline & FEP vs CTL, validation & 1,22 & 1,55 & 1,12 \\
\hline \multirow{3}{*}{ ROC AUC } & SCZ vs CTL, main & 0,67 & 0,81 & 0,66 \\
\hline & SCZ vs CTL, validation & 0,57 & 0,73 & 0,61 \\
\hline & FEP vs CTL, validation & 0,68 & 0,81 & 0,67 \\
\hline
\end{tabular}

Table 1. p-values, fold-changes, and ROC AUC values for the comparisons between the psychiatric and CTL groups.

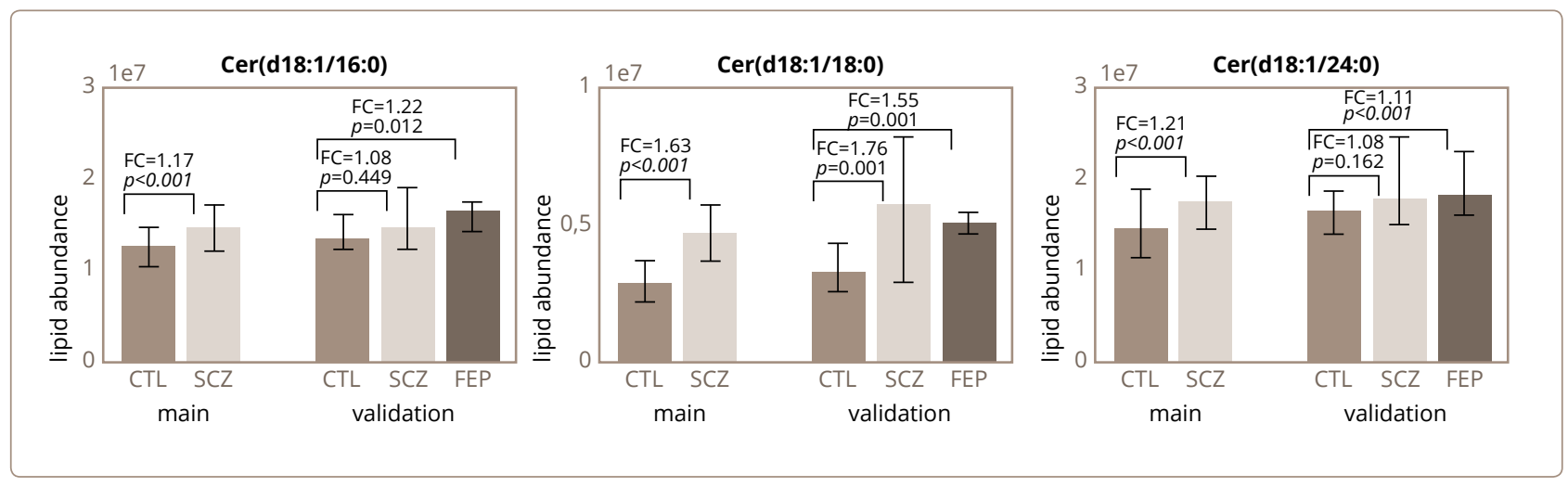

Figure 1. The median and interquartile ranges in sample groups for each of the ceramides' abundances: Cer(d18:1/16:0), $\operatorname{Cer}(\mathrm{d} 18: 1 / 18: 0)$, and Cer(d18:1/24:1). The median abundances in each sample group correspond to the bar heights, and the interquartile range is indicated by the error bars. For each of the ceramide, sample groups are indicated on the bottom, from left to right: CTL main cohort, SCZ main cohort, CTL validation cohort, SCZ validation cohort, FEP validation cohort. The p-values of the Welch t-test and the fold-changes in abundances for the comparisons between the psychiatric and CTL groups are indicated on the plots.

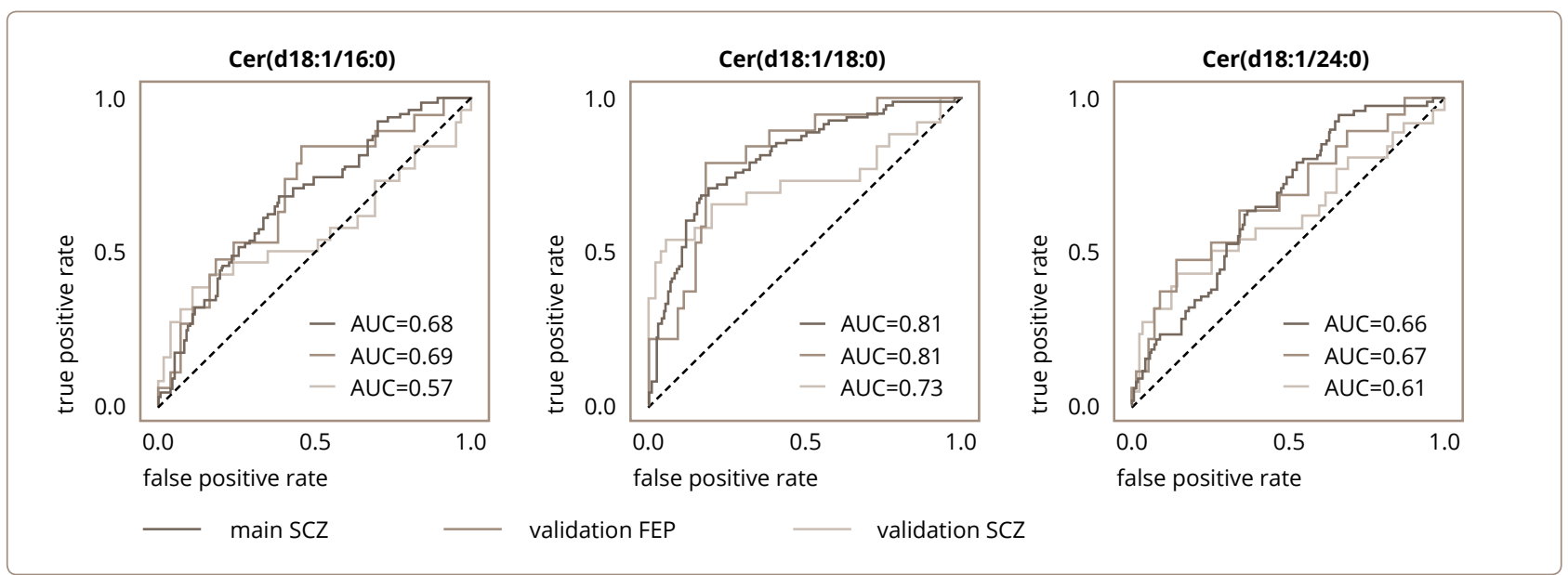

Figure 2. The receiver operating characteristic (ROC) curves for the naïve classifiers that were based on each of the ceramides' abundances: $\operatorname{Cer}(\mathbf{d} 18: 1 / 16: 0), \operatorname{Cer}(d 18: 1 / 18: 0)$, and $\operatorname{Cer}(d 18: 1 / 24: 1)$. Each ceramide species, in conjunction with an abundance threshold, represents a naive classifier, with individuals with abundances higher than the cutoff threshold classified as the psychiatric patient group, and individuals with abundances lower the cutoff - as CTL group. For each ceramide, the ratio of the true positive classifications is plotted against the ratio of false positive classifications for the different cutoff thresholds. Colours correspond to the different classification tasks: main cohort SCZ vs. CTL (dark red), validation cohort FEP vs. CTL (red), validation cohort SCZ vs. CTL (orange). The corresponding areas under the curves (AUCS) are indicated on the plots. 
and $\operatorname{Cer}(\mathrm{d} 18: 1 / 24: 1)$, displayed statistically significant differences in abundance between the SCZ and CTL groups, with all three compounds showing a higher abundance in SCZ (Welch t-test, $p<0.0001$ ) (Figure 1; Table 1). Similarly, the intensities of all three ceramides were elevated in SCZ and FEP patients compared to CTL individuals in the validation cohort. Further, despite reduction in statistical power due to smaller sample size, abundance of all three ceramides differed significantly between FEP and CTL samples (Welch t-test, $p=0.0125,0.000005$, and 0.0255 , respectively), as well as for Cer(d18:1/18:0), between the SCZ and CTL samples (Welch t-test, $p=0.0012$; Figure 1; Table 1).

We then tested the possibility of being able to discriminate between the two groups of individuals, psychiatric patients and controls, based on the abundances of each of the three ceramides. The abundances of each compound, in conjunction with an abundance threshold, represented a naive classifier, with individuals with abundances higher than the cutoff threshold classified as the psychiatric patient group, and individuals with abundances lower than the cutoff as the CTL group. To assess the predictive power of these naive classifiers, we used Area Under the Curve of the Receiver Operator Characteristic (AUC ROC), which reflects, for the different cutoff thresholds, the relationship between the ratio of false positive and true positive classifications. A large AUC (with a maximum of 1) corresponds to a classifier for which, with an appropriate cutoff threshold, the ratio of true positives is higher, while the ratio of false positives remains low. Of the three ceramides, $\operatorname{Cer}(\mathrm{d} 18: 1 / 18: 0)$ showed best performance, as indicated by the fact that it had the highest ROC AUC score (Cer(d18:1/16:0): $A \cup C=0.68 ; \operatorname{Cer}(d 18: 1 / 18: 0): A U C=0.81$; Cer(d18:1/24:1): AUC=0.61; Figure 2; Table 1). We then assessed the performance of these same classifiers when applied to the classification of psychiatric patients versus CTL in the validation cohort. For the three ceramides, the separation of SCZ and CTL was slightly worse than in the main cohort (Cer(d18:1/16:0): AUC=0.57; $\operatorname{Cer}(d 18: 1 / 18: 0)$ : AUC $=0.73 ; \operatorname{Cer}(d 18: 1 / 24: 1)$ : AUC=0.61; Figure 2; Table 1). The classification of FEP versus CTL individuals, however, displayed no decline in accuracy compared to the main cohort performance (Cer(d18:1/16:0): $A U C=69$; Cer(d18:1/18:0): AUC=81; $\operatorname{Cer(d18:1/24:1):~AUC=67;~}$ Figure 2; Table 1), indicating the good generalization capabilities of the separation models.
We next used the abundances of the three ceramides together to construct a logistic regression model separating psychiatric patients from CTL individuals. The model trained on the samples from the main cohort showed a similar accuracy to the best-performing individual ceramide, Cer(d18:1/18:0), but its accuracy in the validation dataset was, in fact, higher (main cohort, SCZ vs CTL: $A U C=0.82$; validation cohort, $S C Z$ vs $C T L$ : $A \cup C=0.81$; FEP vS $C T L: A \cup C=0.83$ ).

\section{DISCUSSION}

Schizophrenia (SCZ) is burdened by a range of metabolic abnormalities. In this work, we have assessed the abundances of three ceramide species, $\operatorname{Cer}(\mathrm{d} 18: 1 / 16: 0)$, Cer(d18:1/18:0), and Cer(d18:1/24:1), in the blood plasma of patients suffering from SCZ and in control individuals with no psychiatric diagnosis. These ceramide species were chosen on account of their emerging role as biomarkers of cardiovascular disease (CVD). ${ }^{18}$ Our results demonstrate that ceramide alterations might be an abnormality common to both SCZ and CVD.

While CVD progression can be affected by environmental factors such as lifestyle, weight, and smoking, ${ }^{5}$ there is evidence for a genetic basis of CVD. ${ }^{19}$ There are also reports of shared genetic risk factors for both SCZ and $C V D,{ }^{6-8}$ with lipid-related genes being highlighted in the literature., ${ }^{9,10}$ Likewise, while ceramides can be affected by lifestyle, diet, and other environmental factors, the human plasma lipidome, and ceramides in particular, were found to have a marked genetic component. ${ }^{20-22}$ The identifications of genes, such as SPTLC3, that show association with both CVD and blood plasma ceramide levels, ${ }^{20}$ but that were also reported in connection to $\mathrm{SCZ}_{1}{ }^{23,24}$ demonstrates the possibility of an intrinsic connection between SCZ, CVD, and ceramide metabolism abnormalities beyond the superficial influences of environmental factors.

Ceramides are structural elements of eukaryotic cell membranes. They also have signalling functions, being involved in processes such as apoptosis and inflammation. ${ }^{25,26}$ Moreover, ceramides are enriched in neural tissues and are vital for the normal functioning of brain cells, in particular. ${ }^{27-29}$ While the exact role of ceramides is not fully elucidated, perhaps the most convincing evidence of their important functional role is the numerous reports of ceramide alterations in various disorders besides CVD, such as diabetes, insulin resistance, 
neurodegenerative disorders, and multiple sclerosis. ${ }^{30,31}$ In a similar manner to CVD, specific ceramide lipid species quantified in blood plasma, including the Cer(d18:1/18:0) compound assessed in this study, have been proposed as biomarkers of depression..$^{32}$ In schizophrenia, ceramide alterations have been reported in the brain, ${ }^{33}$ and mechanisms linking metabolic abnormalities and SCZ through sphingolipids have been proposed. ${ }^{12,34}$

While ceramides in blood plasma have been extensively studied as biomarkers of depression, ${ }^{32}$ surprisingly, we have not been able to find any studies that explicitly focused on ceramides in the blood plasma of SCZ patients. Nevertheless, alterations in the blood plasma of SCZ patients were investigated and reported for other lipid classes. ${ }^{35-47}$ In our work, we demonstrated that the abundance of one particular ceramide previously reported as a reliable depression and CVD biomarker Cer(d18:1/18:0) $)^{18,32}$ - was sufficient to distinguish SCZ from CTL with an AUC higher than 0.8, where this result was further reproduced in an independent cohort of first psychotic episode patients. We also found that the discriminatory power of the other two assessed ceramides, Cer(d18:1/16:0) and Cer(d18:1/24:1), was lower, but the associated differences in abundance between the SCZ and CTL groups was nonetheless statistically significant. We found that the combination of the abundances for the three ceramides in a single model produced moderate improvement in the classification performance compared to the single compound Cer(d18:1/18:0). The model performance achieved in this study is not, however, the best reported for SCZ and CTL group separation models based on other lipid classes allegedly reached $A \cup C=0.98,{ }^{43}$ indicating extensive disruption of lipid metabolism in SCZ.

The limitation of this study was that only three ceramides were identified, whereas there are several hundred different kinds of lipids in an organism. Environmental factors such as lifestyle, weight, and smoking were also not taken into account. This will be pursued in following studies, where more patients will be recruited, and more lipids will be investigated.

\section{Conclusion}

The interplay between SCZ and metabolic abnormalities, such as CVD, remains poorly understood. Genetic studies have hinted at a connection between these disorders through common lipid metabolism alterations. ${ }^{9,10}$ Specific ceramide species have been proposed as biomarkers of CVD, and we found these same ceramides to be altered in SCZ as well. While the mechanism of ceramide alterations in disease is not clear, the systematic study of lipid and other metabolic disruptions that co-occur with SCZ and CVD might help elucidate the connection between these disorders in the future.

\section{Manuscript process:}

Submitted: 06.08.2021

Accepted: 08.09.2021

Published: 30.09 .2021

Funding: This research received no specific grant from any funding agency.

Conflict of interests: The authors declare no conflict of interest.

Authors" contribution: A.Yu. Morozova, Ya.A. Zorkina, D.S. Andreyuk, S.A. Zozulya - performed blood plasma sample collection and cohort descriptions; P.N. Alekseyeva, E.B. Khobta, A.M. Reznik, A.N. Barkhatova - performed patient recruitment and clinical assessment; E.A. Stekolshchikova, N.A. Anikanov - performed the experiments; A.l. Tkachev - performed formal analysis; A.I. Tkachev, Ph.E. Khaitovich - wrote the manuscript; T.P. Klyushnik, G.P. Kostyuk, Ph.E. Khaitovich - designed the study and supervised the work. All authors read and approved the final manuscript.

Acknowledgments: We thank all authors for their contributions to the research.

\section{Correspondence to:}

\section{Anna I. Tkachev}

anna.tkachev@skolkovotech.ru

For citation: Tkachev Al, Stekolshchikova EA, Morozova AYu, Anikanov NA, Zorkina YaA, Alekseeva PN, Khobta EB, Andreyuk DS, Zozulya SA, Barkhatova AN, Klyushnik TP, Reznik AM, Kostyuk GP, Khaitovich PhE. Ceramides: shared lipid biomarkers of cardiovascular disease and schizophrenia. Consortium Psychiatricum. 2021;2(3):35-43. DOI:10.17816/CP101 


\section{References}

1. Mitchell AJ, Vancampfort D, Sweers K, et al. Prevalence of metabolic syndrome and metabolic abnormalities in schizophrenia and related disorders - a systematic review and meta-analysis. Schizophr Bull. 2013;39(2):306-318. doi:10.1093/ schbul/sbr148

2. Correll CU, Solmi M, Veronese N, et al. Prevalence, incidence and mortality from cardiovascular disease in patients with pooled and specific severe mental illness: a large-scale meta-analysis of $3,211,768$ patients and 113,383,368 controls. World Psychiatry. 2017;16(2):163-180. doi:10.1002/wps.20420

3. Walker ER, McGee RE, Druss BG. Mortality in mental disorders and global disease burden implications: a systematic review and meta-analysis. JAMA Psychiatry. 2015;72(4):334-341. doi:10.1001/ jamapsychiatry.2014.2502

4. Olfson M, Gerhard T, Huang C, Crystal S, Stroup TS. Premature Mortality Among Adults With Schizophrenia in the United States. JAMA Psychiatry. 2015;72(12):1172-1181. doi:10.1001/ jamapsychiatry.2015.1737

5. Ringen PA, Engh JA, Birkenaes AB, Dieset I, Andreassen OA. Increased mortality in schizophrenia due to cardiovascular disease - a non-systematic review of epidemiology, possible causes, and interventions. Front Psychiatry. 2014;5:137. doi:10.3389/fpsyt.2014.00137

6. Malan-Muller S, Kilian S, van den Heuvel LL, et al. A systematic review of genetic variants associated with metabolic syndrome in patients with schizophrenia. Schizophr Res. 2016;170(1):1-17. doi:10.1016/j.schres.2015.11.011

7. Hackinger S, Prins B, Mamakou V, et al. Evidence for genetic contribution to the increased risk of type 2 diabetes in schizophrenia. Trans/ Psychiatry. 2018;8(1):252. doi:10.1038/ s41398-018-0304-6

8. Postolache TT, Del Bosque-Plata L, Jabbour S, et al. Co-shared genetics and possible risk gene pathway partially explain the comorbidity of schizophrenia, major depressive disorder, type 2 diabetes, and metabolic syndrome. Am J Med Genet B Neuropsychiatr Genet. 2019;180(3):186-203. doi:10.1002/ajmg.b.32712

9. Andreassen OA, Djurovic S, Thompson WK, et al. Improved detection of common variants associated with schizophrenia by leveraging pleiotropy with cardiovascular-disease risk factors. Am J Hum Genet. 2013;92(2):197-209. doi:10.1016/j.ajhg.2013.01.001

10. So HC, Chau KL, Ao FK, Mo CH, Sham PC. Exploring shared genetic bases and causal relationships of schizophrenia and bipolar disorder with 28 cardiovascular and metabolic traits. Psychol Med. 2019;49(8):1286-1298. doi:10.1017/S0033291718001812

11. Strawbridge RJ, Johnston KJA, Bailey MES, et al. The overlap of genetic susceptibility to schizophrenia and cardiometabolic disease can be used to identify metabolically different groups of individuals. Sci Rep. 2021;11(1):632. doi:10.1038/s41598-020-79964-x

12. Schneider $M$, Levant $B$, Reichel $M$, et al. Lipids in psychiatric disorders and preventive medicine. Neurosci Biobehav Rev. 2017;76(Pt B):336-362. doi:10.1016/j.neubiorev.2016.06.002

13. Soppert J, Lehrke M, Marx N, Jankowski J, Noels H. Lipoproteins and lipids in cardiovascular disease: from mechanistic insights to therapeutic targeting. Adv Drug Deliv Rev. 2020;159:4-33. doi:10.1016/j.addr.2020.07.019

14. Vancampfort $D$, Wampers $M$, Mitchell AJ, et al. A meta-analysis of cardio-metabolic abnormalities in drug naive, first-episode and multi-episode patients with schizophrenia versus general population controls. World Psychiatry. 2013;12(3):240-250. doi:10.1002/wps.20069
15. Pillinger T, Beck K, Stubbs B, Howes OD. Cholesterol and triglyceride levels in first-episode psychosis: systematic review and meta-analysis. Br J Psychiatry. 2017;211(6):339-349. doi:10.1192/bjp.bp.117.200907

16. Misiak B, Stanczykiewicz B, Laczmanski L, Frydecka D. Lipid profile disturbances in antipsychotic-naive patients with first-episode non-affective psychosis: A systematic review and meta-analysis. Schizophr Res. 2017;190:18-27. doi:10.1016/j.schres.2017.03.031

17. Poss AM, Maschek JA, Cox JE, et al. Machine learning reveals serum sphingolipids as cholesterol-independent biomarkers of coronary artery disease. J Clin Invest. 2020;130(3):1363-1376. doi:10.1172/JCl131838

18. Mantovani A, Dugo C. Ceramides and risk of major adverse cardiovascular events: A meta-analysis of longitudinal studies. J Clin Lipidol. 2020;14(2):176-185. doi:10.1016/j.jacl.2020.01.005

19. Ivanova E, Khan A, Liharska L, et al. Validation of the Russian Version of the Positive and Negative Syndrome Scale (PANSS-Ru) and Normative Data. Innov Clin Neurosci. 2018;15(9-10):32-48. PMC6292716

20. Musunuru K, Hershberger RE, Day SM, et al. Genetic Testing for Inherited Cardiovascular Diseases: A Scientific Statement From the American Heart Association. Circ Genom Precis Med. 2020;13(4):e000067. doi:10.1161/HCG.0000000000000067

21. Tabassum R, Ramo JT, Ripatti P, et al. Genetic architecture of human plasma lipidome and its link to cardiovascular disease. Nat Commun. 2019;10(1):4329. doi:10.1038/s41467-019-11954-8

22. Cadby G, Melton PE, McCarthy NS, et al. Heritability of 596 lipid species and genetic correlation with cardiovascular traits in the Busselton Family Heart Study. J Lipid Res. 2020;61(4):537-545. doi:10.1194/jlr.RA119000594

23. Bellis C, Kulkarni $H$, Mamtani M, et al. Human plasma lipidome is pleiotropically associated with cardiovascular risk factors and death. Circ Cardiovasc Genet. 2014;7(6):854-863. doi:10.1161/ CIRCGENETICS.114.000600

24. Kirov G, Zaharieva I, Georgieva L, et al. A genome-wide association study in 574 schizophrenia trios using DNA pooling. Mol Psychiatry. 2009;14(8):796-803. doi:10.1038/mp.2008.33

25. Yamada K, Iwayama Y, Hattori E, et al. Genome-wide association study of schizophrenia in Japanese population. PLoS One. 2011;6(6):e20468. doi:10.1371/journal.pone.0020468

26. Woodcock J. Sphingosine and ceramide signalling in apoptosis. IUBMB Life. 2006;58(8):462-466. doi:10.1080/15216540600871118

27. Gomez-Munoz A, Presa N, Gomez-Larrauri A, et al. Control of inflammatory responses by ceramide, sphingosine 1-phosphate and ceramide 1-phosphate. Prog Lipid Res. 2016;61:51-62. doi:10.1016/j.plipres.2015.09.002

28. Mencarelli C, Martinez-Martinez P. Ceramide function in the brain: when a slight tilt is enough. Cell Mol Life Sci. 2013;70(2):181-203. doi:10.1007/s00018-012-1038-x

29. Olsen ASB, Faergeman NJ. Sphingolipids: membrane microdomains in brain development, function and neurological diseases. Open Biol. 2017;7(5). doi:10.1098/rsob.170069

30. Hussain G, Wang J, Rasul A, et al. Role of cholesterol and sphingolipids in brain development and neurological diseases. Lipids Health Dis. 2019;18(1):26. doi:10.1186/s12944-019-0965-z

31. Kurz J, Parnham MJ, Geisslinger G, Schiffmann S. Ceramides as Novel Disease Biomarkers. Trends Mol Med. 2019;25(1):20-32. doi:10.1016/j.molmed.2018.10.009

32. Turpin-Nolan SM, Bruning JC. The role of ceramides in metabolic disorders: when size and localization matters. Nat Rev Endocrinol. 2020;16(4):224-233. doi:10.1038/s41574-020-0320-5 
33. Dinoff A, Herrmann N, Lanctot KL. Ceramides and depression: A systematic review. J Affect Disord. 2017;213:35-43. doi:10.1016/j. jad.2017.02.008

34. Schwarz E, Prabakaran S, Whitfield $P$, et al. High throughput lipidomic profiling of schizophrenia and bipolar disorder brain tissue reveals alterations of free fatty acids, phosphatidylcholines, and ceramides. J Proteome Res. 2008;7(10):4266-4277. doi:10.1021/ pr800188y

35. Castillo RI, Rojo LE, Henriquez-Henriquez M, et al. From Molecules to the Clinic: Linking Schizophrenia and Metabolic Syndrome through Sphingolipids Metabolism. Front Neurosci. 2016;10:488. doi:10.3389/fnins.2016.00488

36. Cao B, Wang D, Pan Z, et al. Characterizing acyl-carnitine biosignatures for schizophrenia: a longitudinal pre- and posttreatment study. Trans/ Psychiatry. 2019;9(1):19. doi:10.1038/ s41398-018-0353-x

37. Wood PL, Unfried G, Whitehead W, Phillipps A, Wood JA. Dysfunctional plasmalogen dynamics in the plasma and platelets of patients with schizophrenia. Schizophr Res. 2015;161(2-3):506510. doi:10.1016/j.schres.2014.11.032

38. He Y, Yu Z, Giegling I, et al. Schizophrenia shows a unique metabolomics signature in plasma. Trans/ Psychiatry. 2012;2:e149. doi:10.1038/tp.2012.76

39. Kaddurah-Daouk R, McEvoy J, Baillie R, et al. Impaired plasmalogens in patients with schizophrenia. Psychiatry Res. 2012;198(3):347-352. doi:10.1016/j.psychres.2012.02.019

40. Wang D, Sun X, Maziade M, et al. Characterising phospholipids and free fatty acids in patients with schizophrenia: A case-control study. World J Biol Psychiatry. 2021;22(3):161-174. doi:10.1080/156 22975.2020.1769188

41. Kriisa K, Leppik L, Balotsev R, et al. Profiling of Acylcarnitines in First Episode Psychosis before and after Antipsychotic Treatment. J Proteome Res. 2017;16(10):3558-3566. doi:10.1021/acs. jproteome.7b00279
42. Leppik L, Parksepp M, Janno S, et al. Profiling of lipidomics before and after antipsychotic treatment in first-episode psychosis. Eur Arch Psychiatry Clin Neurosci. 2020;270(1):59-70. doi:10.1007/ s00406-018-0971-6

43. Yan L, Zhou J, Wang D, et al. Unbiased lipidomic profiling reveals metabolomic changes during the onset and antipsychotics treatment of schizophrenia disease. Metabolomics. 2018;14(6):80. doi:10.1007/s11306-018-1375-3

44. Wang D, Cheng SL, Fei Q, et al. Metabolic profiling identifies phospholipids as potential serum biomarkers for schizophrenia. Psychiatry Res. 2019;272:18-29. doi:10.1016/j.psychres.2018.12.008

45. Oresic M, Seppanen-Laakso T, Sun D, et al. Phospholipids and insulin resistance in psychosis: a lipidomics study of twin pairs discordant for schizophrenia. Genome Med. 2012;4(1):1. doi:10.1186/gm300

46. McEvoy J, Baillie RA, Zhu H, et al. Lipidomics reveals early metabolic changes in subjects with schizophrenia: effects of atypical antipsychotics. PLoS One. 2013;8(7):e68717. doi:10.1371/ journal.pone.0068717

47. Solberg DK, Bentsen $H$, Refsum $H$, Andreassen OA. Lipid profiles in schizophrenia associated with clinical traits: a five year followup study. BMC Psychiatry. 2016;16:299. doi:10.1186/s12888-0161006-3

48. Cao B, Wang D, Pan Z, et al. Metabolic profiling for water-soluble metabolites in patients with schizophrenia and healthy controls in a Chinese population: A case-control study. World J Biol Psychiatry. 2020;21(5):357-367. doi:10.1080/15622975.2019.1615639

49. Tkachev A, Stekolshchikova E, Anikanov N, et al. Shorter Chain Triglycerides Are Negatively Associated with Symptom Improvement in Schizophrenia. Biomolecules. 2021;11(5). doi:10.3390/biom11050720 